\title{
HOW SCAPHOID FRACTURES ARE TREATED IN BRAZIL
}

\section{COMO SÃO TRATADAS AS FRATURAS DO ESCAFOIDE NO BRASIL}

\author{
Gustavo Chaves Nacif, ${ }^{1}$ Fernando Moises Jose Pedro,${ }^{1}$ Vinicius Ynoe de Moraes, ${ }^{1}$ Marcela Fernandes, ${ }^{1}$ João Carlos Bellot ${ }^{1,2}$ \\ 1. Hospital Alvorada Moema, São Paulo, SP, Brazil. \\ 2. Escola Paulista de Medicina (UNIFESP), São Paulo, SP, Brazil.
}

\section{ABSTRACT}

Objective: To verify how hand surgeons manage scaphoid fractures and their complications. Methods: Two hundred questionnaires were distributed during the $36^{\text {th }}$ Brazilian Hand Surgery Congress (2016). Results: On suspicion of fracture without radiographic confirmation, $57 \%$ of surgeons request a CT or MRI scan, while $43 \%$ opt for immobilization and consecutive radiographs. In stable fractures the preference was for treatment with plaster cast. In fractures with no scaphoid waist displacement, 33\% opt for percutaneous fixation. In displaced waist or proximal pole fractures, $66 \%$ and $99.4 \%$, respectively, opted for surgical treatment. Most surgeons treat waist nonunion with a nonvascularized bone graft. When absorption at the site of nonunion is greater than $4 \mathrm{~mm}, 50 \%$ prefer to use iliac graft and screw fixation. In proximal pole nonunion, the Zaidemberg technique is preferred by $64 \%$. More experienced surgeons are more likely to request tests in occult fractures (63.9\% versus $47.6 \% ; p=0.04)$, and tend to recommend surgery for distal third fractures more frequently (16.4\% versus $4.7 \% ; p=0.02$ ). Conclusions: We have provided an overview of treatment preferences for scaphoid fractures. It should be noted that more experienced surgeons are more likely to request additional tests for occult fractures and to recommend surgical treatment of distal third fractures. Level of Evidence IV,Cross-sectional survey.

Keywords: Scaphoid bone. Fractures, bone. Diagnosis. Pseudarthrosis. Cross-sectional studies.

\section{RESUMO}

Objetivo: Verificar como os cirurgiões da mão conduzem o tratamento da fratura de escafoide e suas complicações. Métodos: Durante o $36^{\circ}$ Congresso Brasileiro de Cirurgia da Mão (2016) foram distribuídos 200 questionários. Resultados: Na suspeita da fratura sem confirmação radiográfica, $57 \%$ dos cirurgiões solicitam TC ou $R M$, enquanto $43 \%$ optam por imobilização e radiografia seriada. Nas fraturas estáveis, a preferência foi tratamento com gesso. Nas fraturas sem desvio da cintura do escafoide, 33\% optam pela fixação percutânea. Nas fraturas desviadas do polo proximal ou da cintura, a opção é o tratamento cirúrgico em $66 \%$ e 99,4\%. A maioria trata a pseudoartrose da cintura com enxerto não vascularizado. Quando a absorção no foco da pseudoartrose é maior que $4 \mathrm{~mm}$, $50 \%$ preferem utilizar enxerto do ilíaco e fixar com parafuso. Nas pseudoartroses do polo proximal, a técnica de Zaidemberg é a preferida por $64 \%$. Os cirurgiões mais experientes têm maior propensão para pedir exames em fraturas ocultas ( $63,9 \%$ versus $47,6 \%$; $p=0,04)$ e tendem a indicar cirurgia com mais frequência para as fraturas do terço distal (16,4\% versus $4,7 \% ; p=0,02)$. Conclusões: Forneceu-se panorama das preferências de tratamento para as fraturas do escafoide. Destaca-se maior tendência de cirurgiões mais experientes para solicitação de exames subsidiários para fraturas ocultas e maior indicação cirúrgica para as fraturas do terço distal. Nível de Evidência IV, Estudo transversal tipo survey.

Descritores: Osso escafoide. Fraturas ósseas. Diagnóstico. Pseudoartrose. Estudos transversais.

Citation: Nacif GC, Pedro FMJ,1 Moraes VY, Fernandes M,1 Bellot JC. How scaphoid fractures are treated in Brazil. Acta Ortop Bras. [online]. 2018;26(5):290-3. Available from URL: http://www.scielo.br/aob.

\section{INTRODUCTION}

The scaphoid is the most commonly fractured carpal bone. In adults, $70 \%$ of scaphoid fractures affect the waist; $20 \%$, the proximal pole; and $10 \%$, the distal pole. Fractures occur mainly in young adults, an economically active population, after low-energy trauma or in association with sports practice. ${ }^{1}$ Given that the scaphoid is the main carpal bone, its integrity is vital for stability and mobility of the wrist. After a fracture, vascularization may be considerably compromised, delaying consolidation or causing non-union, which occurs in approximately $5-10 \%$ of non-displaced fractures of the middle third and may reach $90 \%$ in displaced fractures of the proximal pole.,
Increased risk of non-union is associated with fractures of the proximal pole, fractures with an associated carpal ligament injury, delay in diagnosis, inadequate immobilization, ${ }^{2}$ and smoking. The diagnosis is suggested when there is a fracture of the wrist with hyperextension trauma in young adults who present with pain and volume increase in the anatomical snuff-box. Radiographic examination is indicated in the initial evaluation; however, $16 \%$ to $27 \%$ cases show a false-negative result. More specific examinations such as magnetic resonance imaging (MRI) must be performed in order to shorten the time for diagnosis, thus decreasing the direct and indirect costs of treatment. It is estimated that among every

\section{All authors declare no potential conflict of interest related to this article.}


5 patients, 4 are immobilized unnecessarily until a more precise diagnosis is made. ${ }^{3}$

Classically, the treatment of acute fracture without scaphoid displacement is conservative. However, some authors advocate surgical treatment with percutaneous fixation. This enables a shorter time for immobilization and functional restriction. Although this procedure requires a reasonable learning curve, the low surgical morbidity supports this treatment trend. ${ }^{4}$

Pseudarthroses are traditionally treated via a surgical approach with the use of bone grafts and fixation. Recent studies have shown promising results with percutaneous techniques for fixation and/ or possible arthroscopy. ${ }^{5}$

We have witnessed an evolution in the concepts of treatment of scaphoid fractures and their complications, with less invasive methods that enable more rapid rehabilitation. This evolution in the therapeutic approach to fractures of the scaphoid, coupled with their prevalence in young and productive populations, motivated us to conduct a study. Herein we aimed to verify how experts in hand surgery (certified by the Brazilian Society of Hand Surgery-SBCM) plan the treatment of these fractures and manage their complications.

\section{MATERIALS AND METHODS}

This cross-sectional study was presented at the 36th Brazilian Congress of Hand Surgery (CBCM - 2016, São Paulo, SP). The study was approved by the ethics committee (protocol number CAAE: 65622817.4.0000.5533). A structured questionnaire with 15 objective questions was devised, with focus on therapeutic planning for scaphoid fractures and management of complications, and was applied with the consent of the Scientific Commission of the Congress. To participate in the study, a physician was required to be certified as a hand surgeon by the SBCM, complete the questionnaire, and be enrolled and present at the $36^{\text {th }} \mathrm{CBCM}$.

\section{Intervention}

A questionnaire was developed (Annex) a priori, with dichotomous questions relating to the management of scaphoid fractures (diagnosis, treatment, and complications). The questionnaire was initially applied as a pilot survey to the coauthors of the study, and showed good reproducibility and clarity. Of 200 questionnaires distributed in a convenience sample, 181 were completed, with 5 excluded due to incomplete answers, 14 because they were completed by resident physicians, and 2 because they were completed by non-Brazilians, resulting in a total of 160 for this study.

\section{Statistical analysis}

The previously calculated respondent sample size was 158, considering a $95 \%$ confidence interval and sampling error of $5 \%$, for an expected proportion of $10 \%$ for statistical power. For these calculations we used PASS 8 (Power Analysis and Sample Size System) statistical software - NCSS. ${ }^{6,7}$ To verify differences between proportions among interviewees, we used the chi-square test, with significance level of alpha $<5 \%$.

\section{RESULTS}

Of the interviewees, the majority were from the southeastern region (69\%) and worked in the specialty for more than 5 years (61\%). Regarding the clinical suspicion of scaphoid fracture without radiographic confirmation, $43 \%$ of the interviewees immobilize and reevaluate within 15 days, and $38 \%$ require early MRI. For classification, $56 \%$ use Herbert's method and $33 \%$ prefer to use the anatomical level.
The majority (89\%) of specialists treated stable and non-displaced fractures of the distal third of the scaphoid with plaster immobilization, and $77 \%$ included the thumb, while there was no consensus regarding whether $(48 \%)$ or not $(52 \%)$ to immobilize the elbow.

In stable fractures of the scaphoid waist, the majority (67\%) preferred plaster immobilization; 33\% of respondents treated these fractures surgically using percutaneous fixation with compression screws; $66 \%$ of surgeons treated non-displaced fractures of the proximal pole with percutaneous compression screws (53\% anterograde and $13 \%$ retrograde).

In displaced fractures of the scaphoid waist, the vast majority (99.3\%) used reduction and fixation; of these, 52\% used closed reduction and percutaneous fixation. The preference was for fixation with compression screws (88\%).

The majority of specialists (57\%) used Herbert's classification for treatment planning of scaphoid pseudarthrosis and $17 \%$ used the Slade classification.

In the treatment of scaphoid waist pseudarthrosis, with focal absorption of up to $3 \mathrm{~mm}$, most used bone grafts (68\%), while percutaneous fixation with compressive screws was performed by $32 \%$ of the interviewees. When a gap exceeded $4 \mathrm{~mm}$, the most commonly used techniques included iliac grafting with compressive screw (50\%) or radial grafting with compressive screws (19\%).

For pseudarthrosis of the proximal pole, most (64\%) used a dorsal vascularized graft, followed by a non-vascularized bone graft and compressive screws (16\%).

In the treatment of pseudarthrosis of the waist, $70 \%$ of respondents reported that up to $30 \%$ of cases had functional limitation of the wrist or failure, and $47 \%$ reported up to $60 \%$ restriction in cases involving pseudarthrosis of the proximal pole of the scaphoid. For pseudarthrosis with advanced arthrosis of the wrist, i.e., Scaphoid Nonunion Advanced Collapse (SNAC) type II, 48\% of respondents used carpectomy. The second most common treatment (45\%) was four-corner fusion or partial arthrodesis.

When comparing the responses of less and more experienced surgeons, there was a difference in preferences for 2 scenarios: more experienced surgeons are more likely to request additional examinations for occult fractures (63.9\% versus $47.6 \%$, chi-square, $\mathrm{p}=0.04)$ and tended to perform surgery for fractures of the distal third (16.4\% versus $4.7 \%$, chi-square, $p=0.02$ ). Regarding other items in the questionnaire, there were no differences in management preferences between more and less experienced surgeons (Table 1).

Table 1. Treatment options for fractures of the scaphoid: stratification according to experience (more or less than 5 years).

\begin{tabular}{c|c|c|c|c}
\hline & $\begin{array}{c}\text { More } \\
\text { experienced }\end{array}$ & $\begin{array}{c}\text { Less } \\
\text { experienced }\end{array}$ & P-value & Comparison \\
\hline P1 & $63.9 \%(1)$ & $47.6 \%$ & 0.04 & $\begin{array}{c}\text { Additional examinations (1) } \\
\text { versus immobilization }\end{array}$ \\
\hline P2 & $16.4 \%(1)$ & $4.7 \%$ & 0.02 & surgical (1) versus conservative \\
\hline P3 & $38.1 \%(1)$ & $23.8 \%$ & 0.052 & surgical (1) versus conservative \\
\hline P4 & $64.9 \%(1)$ & $69.8 \%$ & 0.052 & surgical (1) versus conservative \\
\hline P5 & $55.7 \%(1)$ & $49.2 \%$ & 0.42 & bloody (1) versus bloodless \\
\hline P6 & $68.04 \%(1)$ & $68.2 \%$ & 1.0 & graft (1) versus without graft \\
\hline
\end{tabular}

P1: Clinical suspicion of fracture, without confirmation on radiography. P2: Stable and non-displaced fractures of the distal third. P3: Stable and non-displaced fractures of the waist. P4: Non-displaced fractures of the proximal pole. P5: Acute displaced fractures of the waist. P6: Waist pseudarthrosis with gaps in a non-displaced fracture focus of less than $3 \mathrm{~mm}$. 


\section{DISCUSSION}

This work is unprecedented and addresses one of the most important and prevalent subjects in the practice of orthopedics and traumatology. The results aim to show how this condition is treated in Brazil, and thus to provide guidance for management protocols and a basis for research projects.

Our sample was representative, as proven by the distribution of respondents from different states, and the results were similar to those reported by the Brazilian Society of Hand Surgery. Moreover, $61 \%$ of respondents had experience exceeding 5 years working in the area. In relation to the initial approach to wrist trauma without diagnostic confirmation, 2 possible scenarios are well established in the literature: immobilization for up to 15 days $^{8}$ and subsequent reevaluation, or early order for an MRI. ${ }^{9}$ These options were chosen by most in this study. Despite being commonly used in clinical practice, we believe that serial radiography does not have good inter-observer concordance and is not safe for management. ${ }^{10}$ Some authors report similar costs between $\mathrm{MRI}$ and serial radiographic monitoring, without considering the loss of productivity due to unnecessary immobilization. ${ }^{11}$ Therefore, there is a tendency to request early MRI to verify the diagnosis.

Herbert's classification was the method used most by our interviewees, as it discusses and guides treatment of both acute fractures and pseudarthrosis. Other specific classification systems for pseudarthrosis are available, enabling treatment planning for this complication in accordance with the evolution, location, and degree of bone failure, with the objective of providing less invasive treatment options and a possibility of faster rehabilitation. ${ }^{5}$

In relation to stable and non-displaced fractures of the distal pole of the scaphoid, our results are in agreement with the literature; there is consensus about conservative treatment with immobilization for 4-6 weeks. Although only one clinical trial studied use of a plaster cast with or without thumb immobilization, there is no evidence for a difference in the rate of consolidation between these 2 methods. ${ }^{12}$ In relation to immobilization of the elbow, there is also no evidence that the rate of consolidation, the time course, and the complications are different with the 2 treatment methods. ${ }^{13}$ Even with the lack of evidence in the literature, $77 \%$ of specialists prefer to immobilize the thumb. In stable and non-displaced fractures of the scaphoid waist, $62 \%$ of respondents preferred immobilization including the thumb; however, surgical treatment was chosen by $33 \%$ of the specialists, which reflects the demand for early rehabilitation. This trend is supported by the literature, as a systematic review reported that after $2-3$ months, patients treated operatively had significantly better functional outcomes than those treated non-operatively; further improvement was not observed after 6 months of follow-up. ${ }^{4}$ In relation to the duration of absence from work, there is an advantage in favor of surgical treatment.

In the approach to a proximal pole fracture, $66 \%$ used a surgical approach, in keeping with a meta-analysis showing that $34 \%$ of proximal pole fractures treated without surgery evolve to a pseudarthrosis, with a 7.5-fold higher risk, when compared to other fractures of the scaphoid. ${ }^{14}$ In waist fractures with displacement, $99 \%$ of the interviewees chose surgery, consistent with the literature. In a systematic review, a 4-fold increased risk of pseudarthrosis was reported when a displaced fracture was treated with cast immobilization, compared to the risk for an undetected fracture, and the risk of non-consolidation was 17 times greater if a displaced fracture was treated without surgery. ${ }^{15}$

When encountering pseudarthrosis of the scaphoid waist with absorption in the fracture focus of less than $3 \mathrm{~mm}, 32 \%$ respondents preferred to treat with percutaneous fixation using compression screws. There is a trend in the literature for less invasive treatment as early as possible to avoid non-union of the scaphoid. Studies have reported a higher rate of consolidation in less time and with less morbidity, in addition to shorter time of immobilization, with the use of percutaneous techniques compared to open techniques. 5,16 Other treatment choices preferred by about $20 \%$ respondents included iliac grafts and distal radial grafts (Matti-Russe), in agreement with the literature. lliac or distal radial grafts have similar consolidation rates, although the approach using another surgical site can result in further complications. In relation to the type of fixation, both Kirschner wires and autocompression bolts have higher consolidation rates, $91 \%$ and $88 \%$, respectively, than for non-fixation (79\%). In addition, rigid fixation allowed for early mobilization. There was no difference in relation to the dorsal or volar approach. ${ }^{17}$

With absorption or displacement greater than $4 \mathrm{~mm}$ at the focus of the pseudarthrosis, all interviewees preferred an open approach, using non-vascularized grafts, with a large preference for the ilium, although there is no evidence in the literature that there is a higher incidence of consolidation; however, there is a higher likelihood of complications. ${ }^{17}$ For pseudarthrosis of the proximal pole, $74 \%$ of respondents preferred use of a vascularized graft. According to a systematic review, there is no difference in the rate of consolidation with or without the use of a vascularized graft, but the time to union of the pseudarthrosis decreases from 17.7 to 11.9 weeks when scaphoid vascular support is provided. ${ }^{14}$

With regard to complications of fractures of the scaphoid waist, $70 \%$ of the experts expect a failure rate of up to $30 \%$; for pseudarthrosis of the proximal pole, $47 \%$ agree with this rate and another $46 \%$ expect a loss of $60 \%$. With progression to SNAC, the most common surgeries were carpectomy and four-corner arthrodesis, in accordance with the evidence in the literature. ${ }^{18}$

\section{CONCLUSION}

There is no consensus on the need for inclusion of the thumb and elbow in the treatment of non-displaced fractures of the scaphoid waist and distal pole, or in the technique for treatment of pseudarthrosis with small bone failure and the technique of choice for treatment of SNAC. The majority of respondents were found to have a consensus regarding the treatment of non-displaced fractures of the waist and distal pole with plaster casts; surgical treatment of displaced fractures of the waist and all fractures of the proximal pole; the use of bone grafts for pseudarthrosis with any degree of bone failure; and the use of vascularized bone grafts for pseudarthrosis of the proximal pole, even with poor prognosis. The more experienced surgeons tend to request tests with greater accuracy for occult fractures and perform surgery for fractures of the distal third of the scaphoid.

There is a need for additional comparative studies to assess the cost-effectiveness of MRI for early diagnosis, as well as the use of percutaneous fixation of non-displaced fractures of the waist with use of percutaneous fixation technique for treatment of pseudarthrosis with small bone failure.

AUTHORS' CONTRIBUTIONS: Each author made significant individual contributions to this manuscript. JCB (0000-0003-3396-479X) participated in the conception and design of the study, the data acquisition, the data analysis and interpretation, and in the discussions, critical reviews of the intellectual content and approval of the final version. MF (0000-0003-1646-6764)* participated in the design of the questionnaire and the data acquisition. VYM (00000002-4933-4007)* participated in the statistical analysis and data interpretation, and in the revisions and approval of the final version. JRN (0000-0002-0476$8768)^{\star}$ participated in the data acquisition. AO (0000-0003-0115-2236)* participated in the data acquisition. GCN (0000-0002-7881-5475)* participated in the conception and design of the study, the data acquisition, the data analysis and interpretation, and in the discussions, critical reviews of the intellectual content and approval of the final version. *ORCID (Open Researcher and Contributor ID). 


\section{REFERENCES}

1. Kozin SH. Incidence, mechanism, and natural history of scaphoid fractures. Hand Clin. 2001;17(4):515-24.

2. Simonian PT, Trumble TE. Scaphoid nonunion. J Am Acad Orthop Surg. 1994;2(4):185-91.

3. Jenkins PJ, Slade K, Huntley JS, Robinson CM. A comparative analysis of the accuracy, diagnostic uncertainty and cost of imaging modalities in suspected scaphoid fractures. Injury. 2008;39(7):768-74.

4. Shen L, Tang J, Luo C, Xie X, An Z, Zhang C. Comparison of operative and non-operative treatment of acute undisplaced or minimally-displaced scaphoid fractures: a meta-analysis of randomized controlled trials. PLoS One. 2015;10(5):e0125247.

5. Slade JF 3rd, Geissler WB, Gutow AP, Merrell GA. Percutaneous internal fixation of selected scaphoid nonunions with an arthroscopically assisted dorsal approach. J Bone Joint Surg Am. 2003;85-A Suppl 4:20-32.

6. Fleiss JL, Levin B, Paik MC. Statistical Methods for Rates and Proportions. $3^{\text {rd }}$ ed. New York: John Wiley \& Sons; 2003.

7. Newcombe RG. Two-sided confidence intervals for the single proportion: comparison of seven methods. Stat Med. 1998;17(8):857-72.

8. Munk PL, Lee MJ, Logan PM, Connell DG, Janzen DL, Poon PY, et al. Scaphoid bone waist fractures, acute and chronic: imaging with different techniques. AJR Am J Roentgenol. 1997;168(3):779-86.

9. Murthy NS. The role of magnetic resonance imaging in scaphoid fractures. $J$ Hand Surg Am. 2013;38(10):2047-54.

10. Tiel-van Buul MM, van Beek EJ, Broekhuizen AH, Nooitgedacht EA, Davids PH, Bakker AJ. Diagnosing scaphoid fractures: radiographs cannot be used as a gold standard! Injury. 1992;23(2):77-9.

11. Dorsay TA, Major NM, Helms CA. Cost-effectiveness of immediate MR imaging versus traditional follow-up for revealing radiographically occult scaphoid fractures. AJR Am J Roentgenol. 2001;177(6):1257-63.

12. Clay NR, Dias JJ, Costigan PS, Gregg PJ, Barton NJ. Need the thumb be immobilised in scaphoid fractures? A randomised prospective trial. J Bone Joint Surg Br. 1991;73(5):828-32.

13. Alshryda S, Shah A, Odak S, Al-Shryda J, Ilango B, Murali SR. Acute fractures of the scaphoid bone: Systematic review and meta-analysis. Surgeon. 2012;10(4):218-29.

14. Eastley N, Singh H, Dias JJ, Taub N. Union rates after proximal scaphoid fractures; meta-analyses and review of available evidence. J Hand Surg Eur. 2013;38(8):888-97.

15. Singh HP, Taub N, Dias JJ. Management of displaced fractures of the waist of the scaphoid: meta-analyses of comparative studies. Injury. 2012;43(6):933-9.

16. Wozasek GE, Moser KD. Percutaneous screw fixation for fractures of the scaphoid. J Bone Joint Surg Br. 1991;73(1):138-42.

17. Pinder RM, Brkljac M, Rix L, Muir L, Brewster M. Treatment of Scaphoid Nonunion: A Systematic Review of the Existing Evidence. J Hand Surg Am. 2015;40(9):1797-1805.

18. Bisneto EN, Freitas MC, Paula EJ, Mattar Junior R, Zumiotti AV. Comparison between proximal row carpectomy and four-corner fusion for treating osteoarthrosis following carpal trauma: a prospective randomized study. Clinics (Sao Paulo). 2011;66(1):51-5. 